\title{
Telephone Extension Number
}

National Cancer Institute

\section{Source}

National Cancer Institute. Telephone Extension Number. NCI Thesaurus. Code C62139.

The number assigned within an organization to an individual telephone that extends the external telephone number. 